\title{
Prevalence of sleep bruxism in children in primary dentition
}

\author{
Ana de Lourdes Sá de Lira ${ }^{1, *}$ (D), Francisco Dário \\ Carvalho de Sousa', Francisca Janiele de Sousa', \\ Maria Karen Vasconcelos Fontenele ${ }^{1}$, Carlos Kelvin \\ Campos Ribeiro', Luiz Eduardo Gomes Ferreira'
}

${ }^{1}$ State University of Piauí - UESPI, School of Dentistry, Department of Clinical Dentistry, Area of Integrated Clinic, Parnaíba, PI, Brazil.
Corresponding author: Ana de Lourdes Sá de Lira Universidade Estadual do Piauí, Faculdade de Odontologia Rua Senador Joaquim Pires 2076 Ininga. Fone (86) 999595004

CEP: 64049-590 Teresina-PI-Brasil email: anadelourdessl@hotmail.com

Received: August 25, 2020

Accepted: October 29, 2020
Aim: To evaluate the prevalence of sleep bruxism in children between 2 to 6 years old in primary dentition in a public school (A1) and a private school (A2) in the state of Piauí. Method: It was cross-sectional and quantitative study in 370 participants, 180 in A1 and 190 in A2. The questionnaire to help diagnose bruxism was applied to parents. In the clinical examination, dental wear was evaluated, checking for the presence of shiny and polished facets on deciduous incisors and / or molars (palatal surface, incisal edges and working cusps) and the results were noted in the odontogram. Students who had bruxism participated in group 1 (G1) and those who did not have it were in the control group (CG) in both $A 1$ and $A 2$. Results: One hundred and five children had sleep bruxism. Tooth wear was more prevalent in the male gender. Both in A1 and in $\mathrm{A} 2$ and in both genders, wear on primary molars was more frequent than in canines. Conclusion: The prevalence of bruxism in children between 2 and 6 years of age was $28.3 \%$, with a predominance in males. There was an association between sleep bruxism and the habit of sucking a finger, pacifier, bottle use and the habit of awake bruxism. In 98.09\% of the children who had sleep bruxism, teeth pain was found. Keywords: Sleep bruxism. Epidemiology. Child. 


\section{Introduction}

Bruxism is a repetitive jaw-muscle activity characterized by clenching or grinding the teeth and/or by bracing or thrusting the mandible that occurs in adults and children, characterized by clenching or clenching teeth. It can occur during the day, daytime bruxism or at night, sleep bruxism (SB) ${ }^{1}$. A study carried out in a Brazilian city observed the prevalence of sleep bruxism in the preschool children approximately 14 percent. With no difference between genders ${ }^{1}$.

The etiology of bruxism is still undefined, but studies suggest several predisposing factors, including systemic and hereditary factors, of psychological and functional origin, such as: strong emotional tension, family problems, existential crises, state of anxiety, depression and children in the self-affirmation phase ${ }^{2,3}$.

The most common signs and symptoms are: dental wear, marks on the cheek mucosa, fractures of restorations, temporomandibular pain and dysfunction, muscle hypertrophy and headache. In children they can be related to headaches and cause extensive damage to primary teeth, such as pain and tooth wear. As primary dentition has an influence on the development of permanent dentition, regular examination of children is an opportunity to intercept the appearance of disorders of the stomatognathic system ${ }^{4}$.

Although different methods of diagnosis are used to sleep bruxism including the assessment of masseter muscle contraction through bite strip electrode and polysomnography, it is noteworthy that the American Academy of Sleep Medicine (AASM) considers the reports of parents/caregivers to be quite reliable and sufficiently objective for use in epidemiological studies ${ }^{3,5}$.

The diagnosis is based on the reports of family members who describe characteristic sounds generated by the grinding of teeth during sleep, when the questionnaire associated with the clinical examination to identify tooth wear is applied ${ }^{6,7}$.

Preschoolers can develop habits that upset the balance between function and growth. In recent years, bruxism in children has become a growing concern, since more often parents seek out a pediatric dentist with this complaint, in addition, this parafunctional habit has a direct impact on quality of life, as it compromises the sleep period, in addition to be considered a risk factor for temporomandibular disorder and damage to the stomatognathic system ${ }^{8-11}$.

As bruxism is a subconscious reflex that is uncontrolled and mild, it is most often unknown or unnoticed by patients and their families. Thus, it is necessary to establish an early diagnosis of possible changes that may occur, before the vicious cycle results in serious and permanent damage ${ }^{12}$.

Socioeconomic and cultural characteristics may be associated with the prevalence of sleep bruxism. The literature has reported that the prevalence is higher in children of greater socioeconomic power, probably due to the stress they are subjected to with numerous daily educational activities and poor sleep quality of the child, causing stress and anxiety in children ${ }^{3,12}$. 
It is assumed that there is a low prevalence of bruxism in children in primary dentition and ignorance of parents and / or guardians of children with bruxism regarding the damage caused by this harmful oral habit. Knowledge of the distribution and factors associated with the manifestation of sleep bruxism in children in the primary dentition is of considerable importance to be able to draft treatment strategies and public health policies directed at oral health.

Since children at an early age can develop habits that impair the balance between function and growth and there are few studies conducted on children on the topic addressed, it was desired to investigate the prevalence of sleep bruxism in children preschoolers in primary dentition.

The aim of this research was to evaluate the prevalence of sleep bruxism in children between 2 to 6 years old in primary dentition in a public school (A1) and a private school (A2) in the state of Piauí.

\section{Materials and Methods}

It was a cross-sectional study, whose descriptors used were: sleep bruxism, epidemiology, children, prevalence. The sample calculation was based on the target population: children between 2 and 6 years old enrolled, specifically in the preschool phase, from the city of Parnaíba in 2018, totaling 4.087 students and the required sample size was 365 participants. Thus, in order to successfully achieve the objective of the present study, it was based on the survey by the Brazilian Institute of Geography and Statistics, which estimates an estimated 15.000 people in the target population: children living in the city of Parnaíba-Pi aged 2 to 6 years. From this, the sample size formula was performed, resulting in a number of 365. The survey was carried out with 10 more children, totaling 370 , to compensate for the withdrawal of 5 , whose parents did not answer the questionnaire.

This minimum number of participants is considered sufficient considering the proposed analyzes, the 5\% sampling error, and 95\% confidence level, indicating that the probability of the mistake made by the research does not exceed $5 \%{ }^{13}$.

The researchers were provided with a letter of consent from the principals of two public schools (A1) and two private schools (A2) chosen by lot in the municipality of Parnaíba-Piauí, which authorized the development of the research after the ethical approval of the Research Committee. Research Ethics at the State University of Piaui CEP / UESPI number: 3.289.714. This research was guided by the obedience of all the ethical principles that guide the research involving human beings, as foreseen in Resolution $n^{\circ} 466 / 12$ (CNS / MS), having the parents or guardians signed the Informed Consent Form (ICF) and the children signed the Term of Assent, after having been advised that the child's participation was not mandatory, and could withdraw at any time, without any harm to them.

Inclusion criteria were children in primary dentition, between 2 and 6 years of age, with no motor disturbances or psychiatric disorders or no systematic diseases (based on parents'/caregivers' reports), whose parents or guardians and children accepted the research. As exclusion criteria, children under 2 years old, as the primary dentition would not yet be fully formed, and those over 6 years old, because they are already in 
mixed dentition(presence of one or more erupted permanent teeth) and a history of orthodontic treatment.

To standardize the diagnosis of tooth wear, clinical training of examiners was carried out by the professor of the children's clinic at Clinic School of Dentistry (CSD) of the Universidade Estadual do Piauí (UESPI), experienced in epidemiological studies. As a pilot study, 20 children who did not participate in the research were examined to test the methodology and $10 \%$ of the sample was examined twice, with an interval of two weeks, to determine the intra-examiner and inter-examiner agreement, with the Kappa coefficient for inter and intra- examiner agreement being 0.81 and 0.85 , respectively.

The diagnosis of SB was based on the reports of tooth grinding during sleep, as proposed by the AASM for preschool children that include: parents who report an occurrence of audible tooth grinding at night, but no other medical or mental disorders (e.g., sleep-related epilepsy, accounts of abnormal movements during sleep), and no other sleep disorders (e.g., obstructive sleep apnea syndrome) ${ }^{5}$. The children were also submitted to a clinical examination to determine tooth wear, and evaluate its possible association with sleep bruxism. This oral condition was diagnosed in the presence of wear on the incisal surfaces of the anterior teeth, and/or occlusal surfaces of the posterior teeth².

The parents attended a lecture on SB and its clinical manifestations and symptoms, before answering the questionnaire validated applied by the researchers (Figure 1) ${ }^{14}$. Using an age-compatible language, the children received an explanation of how the research would be carried out.

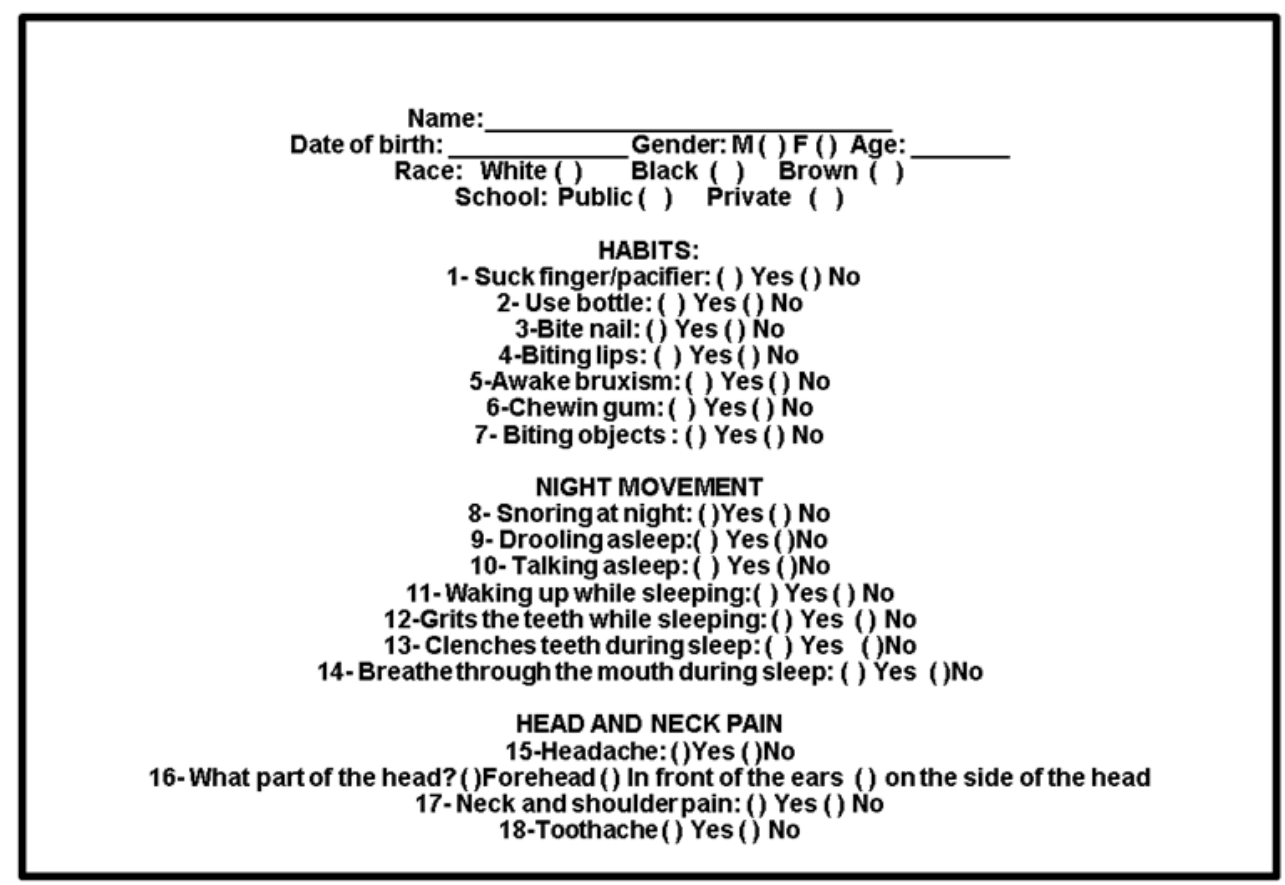

Figure 1. Questionnaire for evaluation of bruxism. 
In a second moment in the school environment, the children were examined under artificial light by two examiners, who used sterilized cotton rollers, a flat mouth mirror and an explorer probe. The children were seated in a school chair, with their head positioned in the examiner's lap. In the clinical examination, dental wear was evaluated, checking for the presence of shiny and polished facets on deciduous incisors and / or molars (palatal surface, incisal edges and working cusps) and the results were noted in the odontogram. Children who had SB participated in group 1 (G1) and those who did not have it were in the control group (CG) in both A1 and A2.

With SPSS, in its version 25, it was possible to perform descriptive statistics, with percentages and frequencies, association analyzes from the chi-square and mean comparisons from the t test, all with the level of significance measured by $p$ value> 0.05 .

\section{Results}

Based on the data collected from 370 children, it was possible to observe that the SB rate was $28.3 \%$, that is, 105 children showed the behavior of grinding and / or clenching their teeth during sleep. Specifically regarding the distribution of the sample in relation to gender and school, its prevalence was observed in Table 1 and Figure 2.

Table 1. characteristics and dental status of subjects.

\begin{tabular}{|c|c|c|c|c|c|c|c|}
\hline \multirow{2}{*}{ Variable } & \multicolumn{2}{|c|}{ Frequency Total } & \multicolumn{2}{|c|}{ G1 } & \multicolumn{2}{|c|}{ CG } & \multirow[t]{2}{*}{$P$ value } \\
\hline & N & $\%$ & $\mathrm{~N}$ & $\%$ & N & $\%$ & \\
\hline Public (A1) & 180 & 48.6 & 41 & 22.8 & 139 & 77.2 & $0.05^{\star}$ \\
\hline Private A2) & 190 & 51.4 & 64 & 33.7 & 126 & 66.3 & $0.05^{*}$ \\
\hline Male & 209 & 56.5 & 63 & 30.1 & 146 & 69.9 & \\
\hline Female & 161 & 43.5 & 42 & 26.1 & 119 & 73.9 & \\
\hline Normal occlusion & 320 & 86.5 & 70 & 21.8 & 250 & 78.2 & $0.01 *$ \\
\hline Malocclusion & 50 & 13.5 & 35 & 70.0 & 15 & 30.0 & \\
\hline Absence dental carie & 335 & 90.6 & 88 & 26.2 & 247 & 73.8 & $0.01 *$ \\
\hline Dental carie & 35 & 9.4 & 17 & 48.5 & 18 & 51.5 & \\
\hline
\end{tabular}

Note: Chi-square test; ${ }^{*} \mathrm{p}<0.05$.

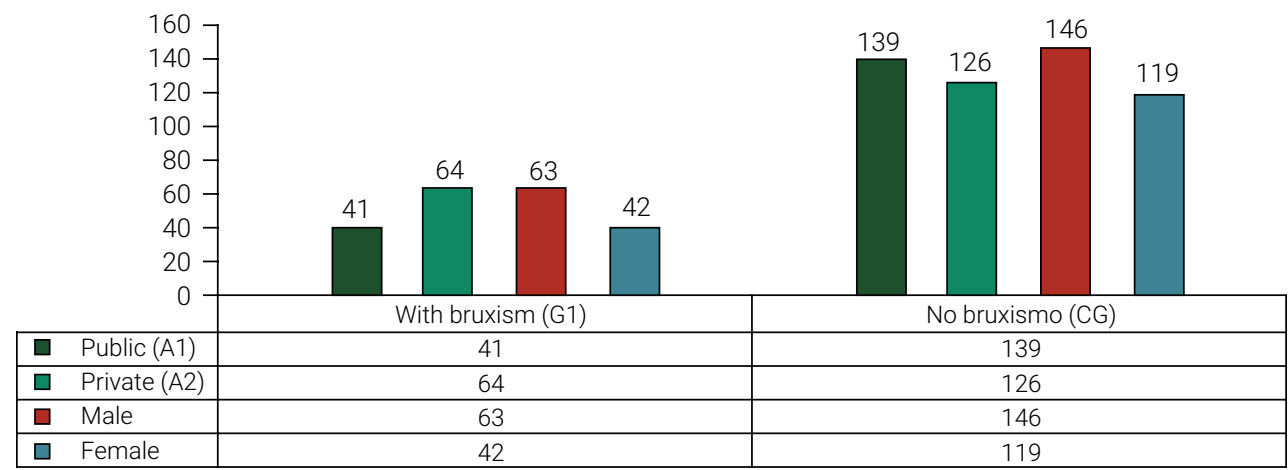

Public (A1)

Private (A2)

Male

Female

Figure 2. Prevalence of bruxism regarding gender and school. 
Based on these values, complemented with statistical chi-square calculations, it was found that in the children of the CG there were no statistically significant differences $(p>0.05)$. However in the children of $\mathrm{G} 1$ there was a difference in terms of gender $(X 2=4.20 ; p<0.05)$, with boys having a higher prevalence and regarding the type of school $(X 2=5.04 ; p<0.05)$ and school A2 showed a higher prevalence of children with bruxism.

Thirty-five children in G1 presented anterior open bite, 25 of them due to the habit of sucking a finger or pacifier and 10 due to mouth breathing. In the CG, all 15 children with this type of malocclusion were due to the finger sucking habit. Only 35 children had caries on the proximal surfaces of the upper incisors (17 in G1 and 18 in G2) (Table 1).

The t test was applied to compare the mean age between $\mathrm{G} 1$ and $\mathrm{CG}$, and it was possible to verify that there was a statistically significant difference $(t=3.47 ; p=0.01)$, with higher mean ages for $\mathrm{G} 1$ (4.81 years; $\mathrm{SD}=0.96$ ) when compared to the CG $(4.38$; $S D=1.27$ ). Table 2 showed the possible etiological factors and side effects and their association with SB.

Table 2. Distribution of harmful habits and symptoms associated with sleep bruxism

\begin{tabular}{|c|c|c|c|c|c|}
\hline $\begin{array}{l}\text { Harmful habits and } \\
\text { symptoms }\end{array}$ & & (G1) & (CG) & Total & $\begin{array}{c}\mathrm{X}^{2} \\
p \text { valor }\end{array}$ \\
\hline \multirow{2}{*}{ Suck finger/pacifier } & Yes & 25 & 92 & 117 & 22.42 \\
\hline & No & 90 & 163 & 253 & $0.01 *$ \\
\hline \multirow{2}{*}{ Use bottle } & Yes & 26 & 109 & 135 & 10.78 \\
\hline & No & 79 & 156 & 235 & $0.01 *$ \\
\hline \multirow{2}{*}{ Bite nail } & Yes & 61 & 125 & 186 & 2.45 \\
\hline & No & 44 & 144 & 184 & 0.12 \\
\hline \multirow{2}{*}{ Biting lips } & Yes & 72 & 171 & 243 & 0.08 \\
\hline & No & 33 & 94 & 127 & 0.78 \\
\hline \multirow{2}{*}{ Awake Bruxism } & Yes & 75 & 66 & 141 & 64.76 \\
\hline & No & 30 & 199 & 229 & $0.01 *$ \\
\hline \multirow{2}{*}{ Chewing gum } & Yes & 102 & 228 & 330 & 5.82 \\
\hline & No & 3 & 37 & 40 & $0.01 *$ \\
\hline \multirow{2}{*}{ Biting objects } & Yes & 63 & 174 & 237 & 2.24 \\
\hline & No & 42 & 91 & 133 & 0.13 \\
\hline \multirow{2}{*}{ Snoring at night } & Yes & 18 & 42 & 60 & 0.24 \\
\hline & No & 87 & 223 & 310 & 0.88 \\
\hline \multirow{2}{*}{ Drooling asleep } & Yes & 18 & 27 & 45 & 2.92 \\
\hline & No & 87 & 238 & 325 & 0.09 \\
\hline \multirow{2}{*}{ Talking asleep } & Yes & 9 & 18 & 27 & 0.25 \\
\hline & No & 96 & 247 & 343 & 0.62 \\
\hline \multirow{2}{*}{$\begin{array}{l}\text { Waking up while } \\
\text { sleeping }\end{array}$} & Yes & 18 & 60 & 78 & 1.79 \\
\hline & No & 97 & 195 & 292 & 0.18 \\
\hline
\end{tabular}

Continue 
Continuation

\begin{tabular}{lccccc}
\hline \multirow{2}{*}{$\begin{array}{l}\text { Breathe through your } \\
\text { mouth }\end{array}$} & Yes & 25 & 38 & 63 & 1.85 \\
\cline { 2 - 6 } & No & 82 & 225 & 307 & 0.17 \\
\hline \multirow{2}{*}{ Headache } & Yes & 48 & 99 & 147 & 1.46 \\
\cline { 2 - 6 } & No & 57 & 166 & 223 & 0.23 \\
\hline \multirow{2}{*}{ Neck and shoulder pain } & Yes & 31 & 68 & 99 & 0.31 \\
\cline { 2 - 6 } & No & 74 & 197 & 271 & 0.58 \\
\hline \multirow{2}{*}{ Toothache } & Yes & 103 & 93 & 196 & 113.88 \\
\cline { 2 - 6 } & No & 2 & 172 & 174 & $0.01^{*}$ \\
\hline
\end{tabular}

Note: Chi-square test; * $p<0.05$

Based on Table 2, with the frequency data, followed by the chi-square test, it was possible to observe an association of SB with the habit of sucking a finger and / or pacifier ( $p=0.01$ ), with 15 children showing such habit. There was also an association between the fact that the child uses a bottle $(p=0.01)$ showing 26 children with SB. There was an association with awake bruxism and SB $(p=0.01)$. This fact was also observed with the majority of children who chew gum $(p=0.01)$. Finally, there was a prevalence of almost all children who have SB, feel pain in the teeth $(p=0.01)$.

According to Table 3, tooth wear was more prevalent in the male gender. Both in A1 and in $\mathrm{A} 2$ and in both genders, wear on primary molars was more frequent than in canines.

Table 3. Distribution of dental wear in relation to schools and gender

\begin{tabular}{lcccccccc}
\hline \multirow{2}{*}{ Variable } & \multicolumn{2}{c}{ Total } & \multirow{2}{*}{ P value } & \multicolumn{2}{c}{ Molars } & \multicolumn{2}{c}{ Canines } & \multirow{2}{*}{ P value } \\
\cline { 2 - 3 } & $\mathbf{N}$ & $\%$ & & $\mathbf{N}$ & $\%$ & $\mathbf{N}$ & $\%$ & \\
\hline A1 & 51 & 48.6 & 5.3 & 35 & 68.6 & 16 & 31.4 & $0.05^{\star}$ \\
\hline A2 & 54 & 51.4 & & 39 & 72.2 & 15 & 27.8 & $0.05^{\star}$ \\
\hline Male & 65 & 61.9 & $0.05^{*}$ & 45 & 69.2 & 20 & 30.8 & $0.05^{\star}$ \\
\hline Female & 40 & 38.1 & & 30 & 75 & 10 & 25 & $0.05^{\star}$ \\
\hline
\end{tabular}

Note: Chi-square test; * $p<0.05$.

\section{Discussion}

Based on the data collected with 370 children, it was possible to observe that the BS rate was $28.3 \%$, corroborating the study by Junqueira et al. ${ }^{15}$, with preschool children, from 2 to 6 years old, whose prevalence was 29.3\%. Approximate values were found by Clementino et al. ${ }^{8}$ and Alves et al. ${ }^{16}$ who found a prevalence of $32.4 \%$ and $25.2 \%$ respectively. Insana et al. ${ }^{17}$ studying preschool children in Kentucky-USA, they found a high prevalence of $36.8 \%$, with greater frequency in the male gender.

In Brazilian researches including older children in mixed dentition, Drumond et al. ${ }^{9}$ and Feitosa et al. ${ }^{10}$ found a higher prevalence, $40 \%$ and $53.2 \%$, respectively. The difference 
between these studies may be explained by the application of different methodologies and/or the differences between the age groups of the patients. The clinical implication of knowing the prevalence of BS is the possibility of informing parents about the importance of early diagnosis and immediate treatment, since parents' knowledge about the subject is fundamental.

In the present study, there was a difference regarding gender, with boys having a higher prevalence of SB, corroborating the study by Sousa et al. ${ }^{11}$. This fact may be related to the fact that boys are more agitated and, in general, motivated to contain their emotions, which would favor the occurrence of involuntary movements ${ }^{18}$. However, in the study by Clementino et al. ${ }^{8}$ there was a higher prevalence in girls.

In this research, it was found that SB was more frequent in children studying in private schools. It is assumed that socioeconomic factors may be associated with the prevalence of SB. Although this association has not yet been clarified, it may be related to the number of daily activities children perform. On the other hand, Serra-Negra et al. ${ }^{7}$ did not detected no significant association between social vulnerability and sleep bruxism, but found that most children without this parafunctional activity belonged to more privileged social classes.

In this study, it was possible to observe an association between SB and the habit of sucking a pacifier / finger. Similar results were observed by Simões-Zenari and Bitar ${ }^{19}$, when they stated that children with a habit of biting their lips present a five-fold increased risk for bruxism, just as the use of a pacifier increases the risk by approximately seven times. Miamoto et al. ${ }^{20}$ found that individuals with sucking habits were four times more likely to develop SB.

There was an association between the fact that the child uses a bottle and presents bruxism. Rodrigues et al. ${ }^{12}$ in a systematic review stated that bruxism in children is associated with the use of a pacifier. Lamenha et al. ${ }^{21}$ identified the connection between digital sucking habits, nail biting, pacifier use and SB. In this research, there was also an association between the fact that the child uses a bottle and presents bruxism. On the other hand, Orengul et al. ${ }^{22}$ did not find an association between the use of a bottle and the presence of SB. Lamenha et al. ${ }^{21}$ also found no relationship of $\mathrm{SB}$ in children with the use of bottles.

In this research, attention is drawn to the association of awake bruxism ( $n=75)$ and SB $(n=105)$. It was observed that the prevalence of almost all children with SB $(n=105)$ experience pain in the teeth $(n=103)$. Probably the painful symptoms are the result of loss of tooth structure (enamel and dentin) during bruxism, whereas tooth wear is more severe in the primary dentition due to a lower degree of mineralization than in the permanent dentition. In addition, only 35 children out of a total of 370 had enamel caries on the proximal surfaces of the upper incisors (17 in G1 and 18 in G2) (Table 1). Goldstein and Auclair ${ }^{23}$ concluded that awake bruxism is associated with tooth clenching instead of grinding teeth awake, suggesting that awake bruxism is more associated with emotional stress than with SB. Countless times it goes unnoticed until a dental emergency occurs, such as pain or fracture.

Although in this research there was no significant correlation between chewing gum and SB, Lamenha et al. ${ }^{21}$ and Orengul et al. ${ }^{22}$ observed that most children who chew 
gum have this habit, especially the female gender. It is noteworthy that there was a statistical correlation between bruxism and oral habits of digital sucking and pacifier. However, Castelo et al. ${ }^{4}$ in their research found a correlation between SB and chewing gum, mouth breathing, nail biting and lip biting habits.

Although polysomnography is the best test for the diagnosis of SB, its high cost makes its use unfeasible, especially in epidemiological investigations. Thus, the present study has limitations that should be addressed. The cross-sectional nature of the design allows the demonstration of associations but not causality. Longitudinal studies should be carried out to gain a better understanding of the factors that influence the occurrence of bruxism in children.

In conclusion, the prevalence of bruxism in children between 2 and 6 years of age was $28.3 \%$, with a predominance in males. There was an association between sleep bruxism and the habit of sucking a finger, pacifier, bottle use and the habit of awake bruxism. In $98.09 \%$ of the children who had sleep bruxism, teeth pain was found.

\section{References}

1. Vieira-Andrade RG, Drumond CL, Martins-Junior PA, Correa-Faria P, Gonzaga GC, Marques LS, et al. Prevalence of sleep bruxism and associated factors in preschool children. Pediatr Dent. 2014; 36(1):46-50.

2. Lobbezoo F, Ahlberg J, Raphael KG, Wetselaar P, Glaros AG, Kato T, et al. International consensus on the assessment of bruxism: Report of a work in progress. J Oral Rehabil. 2018 Nov;45(11):837-844. doi: 10.1111/joor.12663.

3. Gomes MC, Neves ÉT, Perazzo MF, Souza EGC, Serra-Negra JM, Paiva SM, et al. Evaluation of the association of bruxism, psychosocial and sociodemographic factors in preschoolers. Braz Oral Res 2018 Feb;32(1):9-16. doi: 10.1590/1807-3107bor-2018.vol32.0009.

4. Castelo PM, Gavião MB, Pereira JL, Bonjardim LR. Relationship between oral parafunctional/nutritive sucking habits and temporomandibular joint dysfuction in primary dentition. Int J Paediatr Dent. 2005;15(1):29-36. doi: 10.1111/j.1365-263X.2005.00608.x.

5. American Academy of Sleep Medicine. International classification of sleep disorders. Diagnostic and Coding Manual. Westchester, IL: AASM; 2005. Vol. 2. 208p.

6. Lam MH, Zhang J, Li AM, Wing YK. A community study of sleep bruxism in Hong Kong children: association with comorbid sleep disorders and neurobehavioral consequences. Sleep Med. 2011 Aug. 12(7):641-5. doi: 10.1016/j.sleep.2010.11.013.

7. Serra-Negra J M, Ramos-Jorge ML, Flores-Mendoza CE, Paiva SM, Pordeus IA. Influence of psychosocial factors on the development of sleep bruxism among children. Int J Paediatr Dent. 2009 Sep;19(5):309-17. doi: 10.1111/j.1365-263X.2009.00973.x.

8. Clementino MA, Siqueira MB, Serra- Negra JM, Paiva SM, Granville-Garcia AF. The prevalence of sleep bruxism and associated factors in children: a report by parents. Eur Arch Paediatr Dent. 2017 Dec;18(6):399-404. doi:10.1007/s40368-017-0312-x.

9. Drumond CL, Ramos-Jorge J, Vieira-Andrade RG, Paiva SM, Serra-Negra JMC, Ramos-Jorge ML. Prevalence of probable sleep bruxism and associated factors in Brazilian schoolchildren. Int J Paediatr Dent. 2018.29(2):221-7. doi:10.1111/ipd.12443.

10. Feitosa GMA, Félix R C R, Sampaio DC, Vieira-Andrade RG, Santos CCO, Fonseca-Silva T. Bruxism during childhood behavior profile, features of sleep and symptomatology. Rev Bahiana Odonto. 2016;7(2):94-104. doi: 10.17267/2238-2720. 
11. Sousa HCS, Lima MDM, Dantas Neta NB, Tobias RQ, Moura MS, Moura LFAD. [Prevalence and associated factors to sleep bruxism in adolescents from Teresina, Piauí]. Rev Bras Epidemiol. 2018;21:e180002. doi: 10.1590/1980-549720180002. Portuguese.

12. Rodrigues JA, Azevedo CB, Chami VO, Solano MP, Lenzi TL. Sleep bruxism and oral health-related quality of life in children: a systematic review. Int J Paediatr Dent. 2019 Sep;30(2):1-8. doi:10.1111/ipd.12586.

13. Luchesa CJ, Chaves Neto A. [Calculation of sample size in administration surveys]. Curitiba: Edição do autor; 2011. 27p. Portuguese.

14. Owens JA, Spirito A, McGuinn M. The children's sleep habits questionnaire (CSHQ): psychometric properties of a survey instrument for school-aged children. Sleep. 2000;23(8):1043-51. doi: 10.1037/t33022-000.

15. Junqueira TH, Nahás-Scocate ANR, Valle-Corott JM, Conti ACCF, Trevisan S. Association of infantile bruxism and the terminal relationships of the primary second molars. Braz Oral Res. 2013 Jan;27(1):42-7. doi:10.1590/S1806-83242013000100008.

16. Alves CL, Fagundes DM, Soares PBF, Ferreira MC. Knowledge of parents/caregivers about bruxism in children treated at the pediatric dentistry clinic. Sleep Sci. 2019;12(3):185-9. doi: 10.5935/1984-0063.20190083.

17. Insana S, Gozal D, McNeil DW, Montgomery-Downs HE. Community based study of sleep bruxism during early childhood. Sleep Med. 2012;14(2):183-8. doi:10.1016/j.sleep.2012.09.027.

18. Renner AC, Silva AA, Rodriguez JD, Simões VM, Barbieri MA, Bettiol H. Are mental health problems and depression associated with bruxism in children? Community Dent Oral Epidemiol. 2012 Nov;40(3):277-87. doi: 10.1111/j.1600-0528.2011.00644.x.

19. Simões-Zenari M, Bitar M L. [Factors associated to bruxism in children from 4-6 years]. Pro Fono. 2010;22(4):465-72. doi:10.1590/s0104-56872010000400018. Portuguese.

20. Miamoto CB, Pereira LJ, Ramos-Jorge ML, Marques LS. Prevalence and predictive factors of sleep bruxism in children with and without cognitive impairment. Braz Oral Res. 2011 Sep-Oct;25(5):439-45. doi:10.1590/s1806-83242011000500011.

21. Lamelha RML, Cavalcanti MCC, Mello LF, Vilela MH, Santos-Junior VE. Probable sleep bruxism in children and its relationship with harmful oral habits, type of crossbite and oral breathing. J Clin Pediatr Dent. 2020;44(1):66-9. doi:10.17796/1053-4625-44.1.12.

22. Orengul AC, Tarakcioglu MC, Gormez V, Akkoyun S, Zorlu A, Aliyeva N, et al. Duration of breastfeeding, bottle-feeding, and parafunctional oral habits in relation to anxiety disorders among children. Breastfeed Med. 2018 Nov;14(1):57-62. doi:10.1089/bfm.2018.0013.

23. Goldstein RE, Auclair WC. The clinical management of awake bruxism. J Am Dent Assoc. 2017 May;148(6):387-91. doi:10.1016/j.adaj.2017.03.005. 